\title{
Design analysis and Commissioning Of High Mast Lighting Poles
}

\author{
${ }^{1 .}$ Syed Ibrahim Dilawer, ${ }^{2 .}$ Md. Abdul Raheem Junaidi, ${ }^{3}$ Dr.S.Nawazish \\ Mehdi, ${ }^{4}$ G.M. Sayeed Ahmed \\ 1. Research Assistant, Muffakham jah college of engineering and Technology, Hyderabad, 500034. \\ 2. Assistant Professor, Muffakham jah college of engineering and Technology, Hyderabad,500034. \\ 3. Professor, Muffakham jah college of engineering and Technology, Hyderabad, 500034, \\ 4. Senior Assistant Professor, Muffakham jah college of engineering and Technology, Hyderabad,500034,
}

\begin{abstract}
Along a major highway, luminaire pole structures may be seen every 101 of a mile.From documented cases, it appears that these structures started to experience fatigue problems in the last three decades. The general public might not be aware of the problem, because if such a failure occurs, the structure is replaced. Those working in the fatigue area realize that this issue is a serious matter[15][16]. Clearly, the damage is costly, costing up to thousands of dollars per occurrence. For this purpose, a high mast lighting poles are fabricated using steel due to its high strength, ductilityproperty and wear resistance. The high mast structure (HMS) has the characters of light weight and high cost efficiency. It possess large ratio of height $(H)$ to least horizontal dimension (D) that makes it more slender and wind-sensitive than any other structures[17]. Therefore, the purpose of this research is to design optimal high mast poles taking into account its specification, environmental conditions for placement and economy. Initially, among various pole designs, the high mast pole is considered to be in tapered section as it is more reliable and economical. Then, analysis is performed in solid works by keeping the base section to be fixed and applying compressive load on the top section of the pole due to heavy weight of cantilever mast arm and luminaire. This project illustrates the theoretical basis and the analytical development of the high mast lighting poles.
\end{abstract}

Keywords: High mast lighting poles, luminaire, Optimization, stress, deformation, factor of safety.

\section{Introduction}

A variety of options are available to the designer when selecting luminaire equipment to satisfy the desired design criteria. The designis performed to ensure that the selected equipment meets standard hardware designs. Specialized equipment can significantly increase installation and maintenance costs, thereby reducing the cost effectiveness of the lighting system. In addition to the electrical detailed drawings and the LAASMA Standard Specifications for Road and Bridge Construction, the following sections provide guidance on lighting equipment Foundations.

1.1 Material:- All foundations for permanent installations should be made with Class "DD" Portland cement concrete. For material compilation, mild steel is preferred due to its various advantages compared to other materials as listed below:

a. Other than maximum limit of $2 \%$ carbon in the manufacture of carbon steel, the proportions of manganese $(1.65 \%)$, copper $(0.6 \%)$ and silicon $(0.6 \%)$ are fixed, while the proportions of cobalt, chromium, niobium, molybdenum, titanium, nickel, tungsten, vanadium and zirconium are not [11].

b. A high amount of carbon makes mild steel different from other types of steel. Carbon makes mild steel stronger and stiffer than other type of steel. However, the hardness comes at the price of a decrease in the ductility of this alloy. Carbon atoms get affixed in the interstitial sites of the iron lattice and make it stronger.

c. What is called as mildest grade of carbon steel or 'mild steel' is typically carbon steel, with a comparatively mild amount of carbon $(0.16 \%$ to $0.19 \%)$. It has ferromagnetic properties, which make it ideal for manufacture of electrical devices and motors.

d. The calculated average industry grade mild steel density is $7.85 \mathrm{gm} / \mathrm{cm}^{3}$. Its Young's modulus, which is a measure of its stiffness is around 210,000 Mpa.

e. Mild steel is the cheapest and most versatile form of steel and serves every application which requires a bulk amount of steel.

f. The high amount of carbon, also makes mild steel vulnerable to rust. Naturally, people prefer stainless steel over mild steel, when they want a rust free technology. Mild steel is also used in construction as structural steel. It is also widely used in the car manufacturing industry[11][18]. 
1.2. Design:-The electrical detailed drawings and the Standard Specifications provides the design details for foundation depth, width, reinforcing, etc., for conventional light standards. If high-mast lighting is used, foundations typically require specialized designs and soil surveys be performed to ensure adequate support. Check with the Geotechnical Section for additional guidance. By definition, lighting design according to the illumination method relies on the amount of light flux reaching the pavement and the uniformity of the light on the pavement surface [1] [4]. The steps in the design process are as follows:

A. Determination of the foot-candle value by assessing the facility to be lighted.

B. Selecting the type of light source (Type I-V).

C. Selecting light source size and mounting height.

D. Selecting luminaire type.

E. Determining luminaire spacing and location.

F. Checking for design adequacy.

1.3. Placement:- It provides the Department's criteria for the placement of light standards relative to the roadway. Light Standards (Poles) a major factor in highway lighting design is the selection of the luminaire and the mounting height. Higher mounting heights usually reduce the number of light standards required and enhance illumination uniformity [18]. The Standard Specifications, the electrical detailed drawings, and the latest edition of the Standard Specifications for Structural Supports for Highway Signs, Luminaires and Traffic Signals provide the Department' $\mathrm{s}$ criteria for light standards.

1.4 High-Mast Lighting Design:- In general, the design of high-mast lighting systems consists of the same design procedures as discussed in starting of design. In addition, consider the following:

1.4.1 Light Source:Generally, a $1000 \mathrm{~W}$ high pressure sodium light source should be used. The number of luminaires required will be determined by the area to be lighted. As a general starting point, it can be assumed that mounting heights of $100 \mathrm{ft}(30 \mathrm{~m})$ will require $400,000 \mathrm{~lm}, 600,000 \mathrm{~lm}$ for mounting heights of $115 \mathrm{ft}$ to $130 \mathrm{ft}(35 \mathrm{~m}$ to $40 \mathrm{~m})$ and $800,000 \mathrm{~lm}$ for mounting heights of $150 \mathrm{ft}(45 \mathrm{~m})$. The number of luminaires per pole typically ranges from 4 to 6 luminaires [2].

1.4.2. Mounting Heights: High-mast lighting can range from $80 \mathrm{ft}$ to $200 \mathrm{ft}(24 \mathrm{~m}$ to $60 \mathrm{~m})$. In general, heights of $100 \mathrm{ft}$ to $160 \mathrm{ft}(30 \mathrm{~m}$ to $50 \mathrm{~m})$ have proved to be the most practical. Greater heights require more luminaires to maintain illumination levels. However, greater heights allow for fewer poles and provide better luminance uniformity.

1.4.3. Location: In determining the location for high-mast poles, the designer should review the plan view of the area to determine the more critical areas requiring lighting. In selecting the appropriate luminaire supports for high-mast lighting, consider the following:

a. Critical Areas: Mast poles should be located so that the highest localized levels of illumination fall within the critical traffic areas (e.g., freeway/ramp junctions, ramp terminals, merge points).

b. Roadside Safety: Mast poles should be located a sufficient distance from the roadway so that the probability of a collision is virtually eliminated. They also should not be placed on the end of long tangents.

c. Signs: Masts should be located so that they are not within the driver's direct line of sight to highway signs.

1.4.4. Design: There are generally two methodologies for checking the adequacy of uniformity - the point-bypoint method and the template method. The point-by- point method checks illumination by using the manufacturer's isofootcandle (isolux) diagram. The total illumination at a point is determined by the sum of the contributions of illumination from all mast assemblies within the effective range of the point. Due to the numerous calculations, a computer should be used to make these determinations. The template methodology uses isofootcandle (isolux) templates to determine the appropriate locations for mast supports. The templates may be moved around to ensure that the minimum maintained. Illumination is provided and the uniformity ratio has been satisfied. Give consideration to adjacent land use during the analysis. The FHWA publication Roadway Lighting Handbook provides an example of using the template methodology for a high-mast lighting design[17]. 1.4.5. Navigable Airspace: Where lighting projects are being considered in close proximity to an active airfield or airport, the designer should consider the impact luminaire height has on navigable airspace.

\section{Computational Methodology}

A study manufacturing of different high mast poles with its specification, environmental conditions for placement, economy and commissioning was being carried out and found taper circular hollow section to be optimum. The material is selected as mild steel due to its properties as exhibited in graph. 1.By this developing procedure of finding diameters of high mast pole and foundation bolts by considering circular section of pole has being done and analyses is carried out in solid works (CosmosXpress) by fixing the base section and applying compressive load on the top section of the pole. By which we obtain various stress, strain and deformation relations shown in Fig.2 and Fig.3. This paper illustrates the theoretical basis and the analytical 
development of the high mast lighting poles. High mast lighting structures are being used to provide illumination for large intersections, particularly for highways located in rural areas. The Fig.1 shows the top portion of the High mast lighting poles which is drawn on Auto-cad.

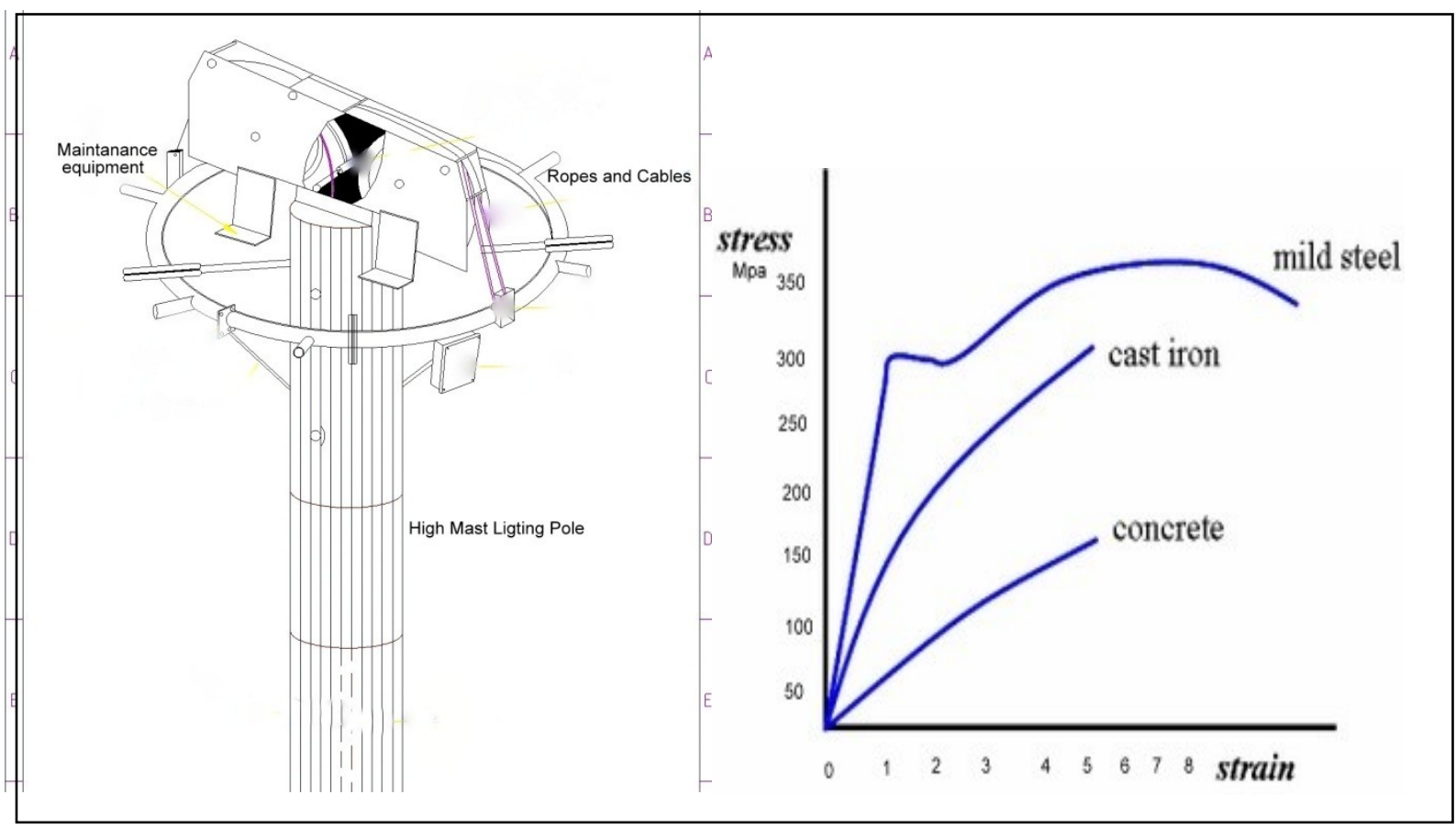

Fig.1 High Mast Top Details

Graph.1

\subsection{Design Calculation:}

Assuming the given section to be circular then we can obtain the diameter for top section as:

For Hyderabad max wind speed $\mathrm{V}_{\mathrm{B}}=180 \mathrm{~km} / \mathrm{hr} \quad=180 \times 1000 / 3600=50 \mathrm{~m} / \mathrm{sec}$

$\mathrm{K}_{1}=$ risk co-efficient (according to standard table [14]) $=1.05$ \{i.e., life of structure in 100 years\}

$\mathrm{K}_{2}$ =terrain factor (for building size in between 15-50m [14])for $\mathrm{h}=16 \mathrm{~m}, \mathrm{~K}_{2}=1.01$

The ground is assumed to be plain, so the topography factor is: $\mathrm{K}_{3}=1+\mathrm{C}_{\mathrm{S}}$ Where $C_{S}=\frac{Z}{L}=0$

$$
\mathrm{K}_{3}=1
$$

Design wind speed $\mathrm{V}_{\mathrm{Z}}=\mathrm{k}_{1} \times \mathrm{k}_{2} \times \mathrm{k}_{3} \times \mathrm{V}_{\mathrm{B}}=1.05 \times 1.01 \times 1 \times 50=53.025 \mathrm{~m} / \mathrm{sec}$

Design wind load including lattern carriage weight $=0.6 \times \mathrm{V}_{\mathrm{Z}}^{2}=0.6 \times(53.025)^{2}=1686.99 \simeq 1687 \mathrm{~N}$

$\mathrm{W}=1687 \mathrm{~N}$; assume $\frac{D}{d}=1.077 ; \mathrm{D}=$ Base diameter, $\mathrm{d}=$ Top Diameter

We know that, from flexural rigidity relation:

$$
\frac{M}{L}=\frac{S}{Y} M=W \times \frac{L}{2} \quad 1687 \times 8=13,496 \mathrm{~N}-\mathrm{m}
$$

Moment of inertia, $I=\frac{P}{64} \times\left(\mathrm{D}^{4}-\mathrm{d}^{4}\right) ; I=\frac{P}{64} \times\left((1.077 \mathrm{~d})^{4}-\mathrm{d}^{4}\right)=1.718 \times 10^{-5} \mathrm{~d}^{4} \quad$ for mild steel $\mathrm{s}=115 \mathrm{~N} / \mathrm{mm}^{2}$ \}

$$
\begin{aligned}
& \frac{M}{I}=\frac{S}{Y}=\frac{13496}{1.718 \times 10-5 \times \mathrm{d} 4}=\frac{115}{d / 2} \\
& \mathrm{~d}^{3}=34154983.04 ; \mathrm{d}=324.5 \simeq 325 \mathrm{~mm} \\
& \mathrm{D}=\mathrm{d} \times \mathrm{t}=325 \times 1.077=350 \mathrm{~mm}
\end{aligned}
$$

Now, bending moment: $\quad \mathrm{S}_{\mathrm{b}}=\mathrm{W} \times \mathrm{e} / \mathrm{z}=1687 \times 50 / 109.53=770 \mathrm{~N} / \mathrm{mm}^{2}$

Finding the diameter using tensile stress in the foundation bolt, we have:

$\mathrm{N}=4, \mathrm{~d}=350 \mathrm{~mm}, \mathrm{D}=460 \mathrm{~mm}, \mathrm{~W}=1687 \mathrm{~N}, \mathrm{~L}=16 \mathrm{~m}, \mathrm{~s}_{\mathrm{t}}=60 \mathrm{~N} / \mathrm{mm}^{2}$

$$
\begin{aligned}
& \left.\mathrm{W}_{\mathrm{t}}=2 \mathrm{~W} \times \mathrm{L} / \mathrm{n} \times \frac{\mathrm{R}+\mathrm{rcos}(180 / \mathrm{n})}{2 \mathrm{R}^{2}+\mathrm{r}^{2}}\right\} \\
& \mathrm{W}_{\mathrm{c}}=2 \times 1687 \times 16000 / 4 \times\left\{\frac{230+175 \cos (45)}{2230^{2}+175^{2}}\right\}=34994.5 \mathrm{~N}
\end{aligned}
$$

Now stress in foundation bolt is taken ass $=60 \mathrm{~N} / \mathrm{mm} 2$

$$
\begin{aligned}
& \mathrm{W}_{\mathrm{t}}=\mathrm{p} / 4 \times \mathrm{d}_{\mathrm{b}}{ }^{2} \times \mathrm{S}_{\mathrm{t}} \\
& \mathrm{D}_{\mathrm{b}}{ }^{2}=34994.5 /(\mathrm{p} / 4 \times 60)=742.6=\mathrm{d}_{\mathrm{b}}=27.25 \mathrm{~mm}
\end{aligned}
$$


Hence, selecting $25 \mathrm{~mm}$ as $25-30 \mathrm{~mm}$ foundation bolts are suitable for this safe design.

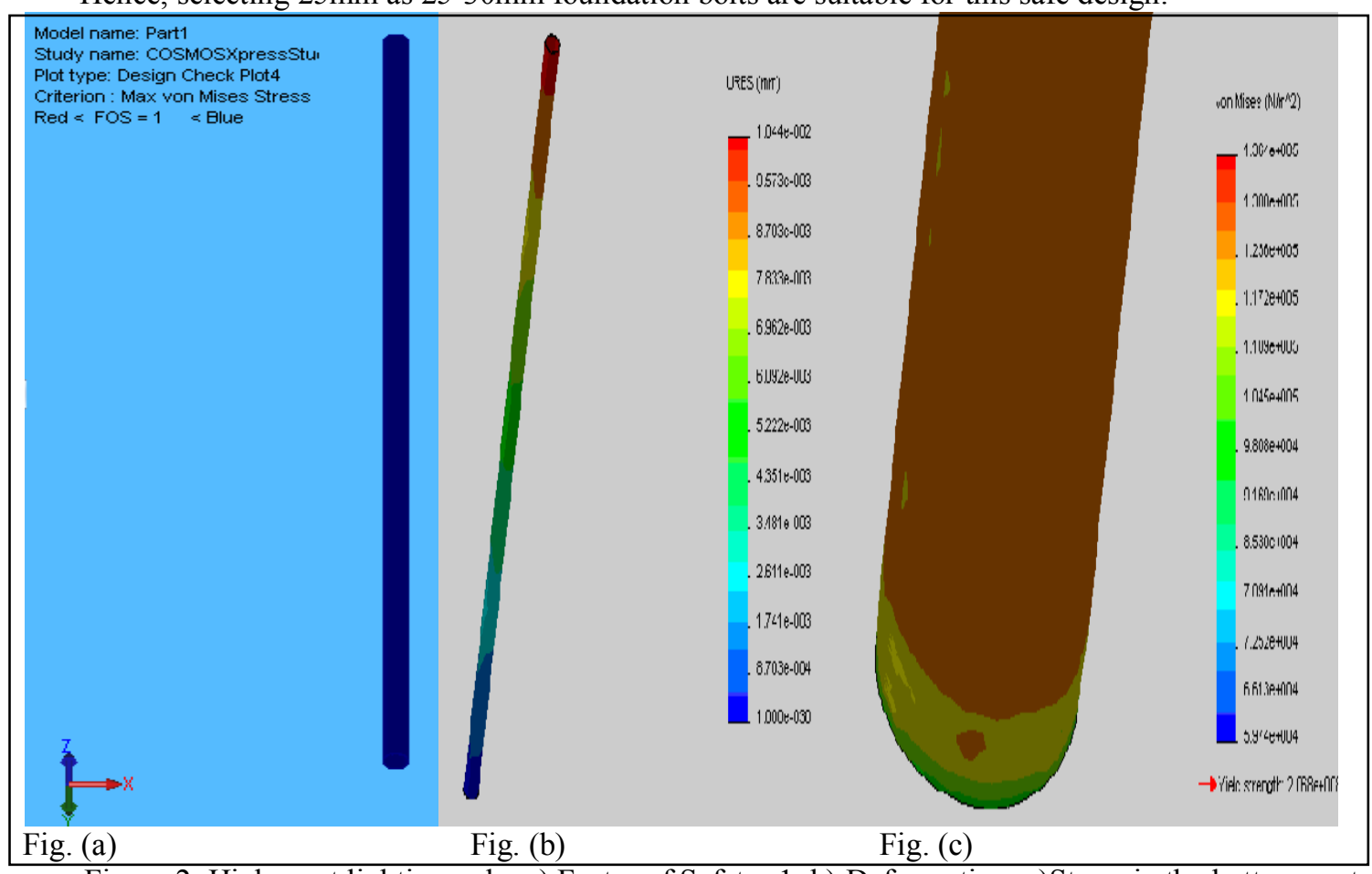

Figure 2: High mast lighting pole; a) Factor of Safety $=1, \mathrm{~b}$ ) Deformation, c)Stress in the bottom part of the high mast pole which is in compression:

Table 1: MaterialProperty :

\begin{tabular}{|l|l|l|l|}
\hline \multicolumn{1}{|c|}{ Body Name } & \multicolumn{1}{c|}{ Material } & \multicolumn{1}{c|}{ Mass } & \multicolumn{2}{c|}{ Volume } \\
\hline High mast pole & [Mild steel] AISI 304 & $12817.7 \mathrm{~kg}$ & $1.60221 \mathrm{~m}^{\wedge} 3$ \\
\hline Property Name & Value & Units \\
\hline Elastic modulus & $1.9 \mathrm{e}+011$ & $\mathrm{~N} / \mathrm{m}^{\wedge} 2$ \\
\hline Poisson's ratio & 0.29 & $\mathrm{NA}$ \\
\hline Mass density & 8000 & $\mathrm{~kg} / \mathrm{m}^{\wedge} 3$ \\
\hline Yield strength & $2.0681 \mathrm{e}+008$ & $\mathrm{~N} / \mathrm{m}^{\wedge} 2$ \\
\hline
\end{tabular}

Table 2: Study Property

\begin{tabular}{|l|l|}
\hline \multicolumn{1}{|c|}{ Mesh Information } & Solid Mesh \\
\hline Mesh Type: & Standard \\
\hline Mesher Used: & On \\
\hline Smooth Surface: & 4 Points \\
\hline Element Size: & $117.01 \mathrm{~mm}$ \\
\hline Tolerance: & $5.8506 \mathrm{~mm}$ \\
\hline Quality: & High \\
\hline Number of elements: & 8693 \\
\hline Number of nodes: & 17413 \\
\hline
\end{tabular}




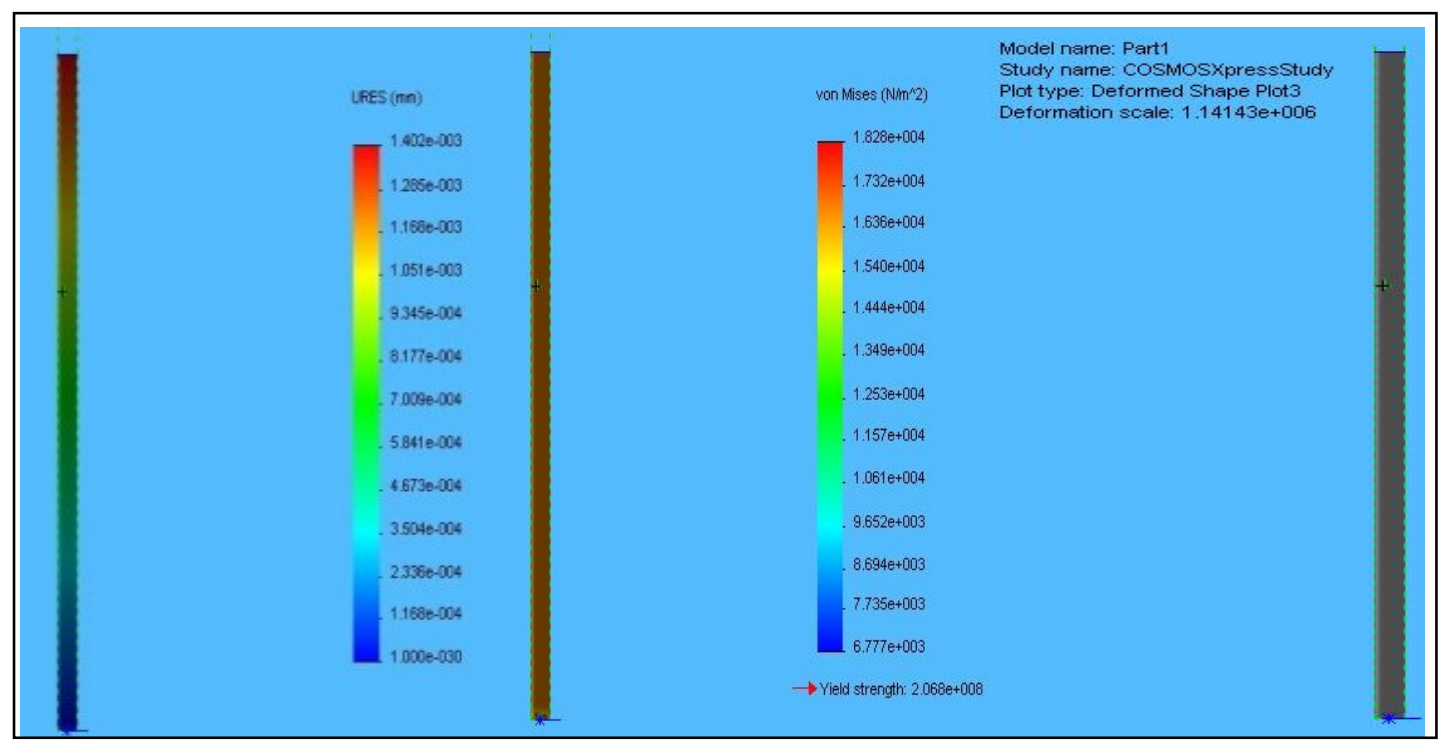

Fig. (a)

Fig. (b)

Fig. (c)

Figure 3: High mast lighting pole; a) Stress-Plot, b) Displacement, c) Deformation

Table 3a. Stress

Table 3b. Deformation

\begin{tabular}{|c|c|c|c|c|c|c|c|c|c|}
\hline Type & Min & Location & $\operatorname{Max}$ & Location & Type & Min | & Location & Max & Location \\
\hline $\begin{array}{l}\text { von } \\
\text { Mises, } \\
\text { Stress }\end{array}$ & $\begin{array}{l}6777.12 \\
\mathrm{~N} / \mathrm{m} / 2\end{array}$ & $\begin{array}{l}(-175 \\
\mathrm{mm}, \\
-2.17349 \\
\mathrm{~mm}, \\
0 \mathrm{~mm})\end{array}$ & $\begin{array}{l}18277.3 \\
\mathrm{~N} / \mathrm{m}^{\wedge} 2\end{array}$ & $\begin{array}{l}(-87.5 \\
\mathrm{mm}, \\
149.381 \\
\mathrm{~mm}, \\
175.182 \\
\mathrm{~mm})\end{array}$ & $\begin{array}{l}\text { URES: } \\
\text { Resultant } \\
\text { Displacement }\end{array}$ & $\begin{array}{l}0 \\
\mathrm{~mm}\end{array}$ & $\begin{array}{l}(87.5 \\
\mathrm{mm}, \\
-153.728 \\
\mathrm{~mm}, \\
0 \mathrm{~mm})\end{array}$ & $\begin{array}{l}0.00140177 \\
\mathrm{~mm}\end{array}$ & $\begin{array}{l}(26.1321 \\
\mathrm{mm}, \\
246.457 \\
\mathrm{~mm}, \\
16000 \\
\mathrm{~mm})\end{array}$ \\
\hline
\end{tabular}

\subsection{Intelligent street lighting}

\section{Optimization And Commissioning Of Lighting Poles}

Intelligent street lighting technology has now matured, providing a cost-effective approach to managing municipal street lighting. Commissioning is systematic process for achieving, verifying, and documenting that the facility and its systems, subsystems, and equipment are planned, designed, installed, and tested, and are capable of being operated and maintained according to an Owner's Project Requirements (OPR) document.The 4.4 million streetlights in the US ten largest metropolitan statistical areas use an estimated 3 billion $\mathrm{kWh}$ of electricity annually, producing the equivalent of 2.3 million metric tons of $\mathrm{CO}_{2}$. If an achievement of 50 percent reduction in powerisused, this amounts to a saving of 1.5 billion $\mathrm{kWh}$ or 1.1 million metric tons of $\mathrm{CO}_{2}$. Times are changing for municipal lighting management, with greater public scrutiny [5]. The key drivers for change are:

a. Economic: Against a backdrop of global economic slowdown, funding is becoming limited. Streetlights are among a city's most important and expensive assets, typically accounting for a third of its electricity bill. With energy prices increasing, this is driving the demand for energy-conserving technologies for municipal lighting. Maintenance costs are also increasing, with huge numbers of lamps nearing the end of their serviceable life [17]. b. Environmental: The Kyoto Protocol compels signatory states to implement rigorous energy conservation programs. This, in turn, puts pressure on municipal bodies to reduce their $\mathrm{CO}_{2}$ emissions. In addition, ecologically minded governments are responding to the reports of light pollution adversely affecting the nocturnal natural environment [5] [7].

c. Intelligent Lighting: An intelligent outdoor lighting system can help local communities do their part in meeting this global challenge. Intelligent lighting systems utilize the latest technologies to optimize the light intensity according to the situation by dimming the lamp. All lamps can be communicated with, so their condition can be assessed remotely and, if necessary, the lamp controlled remotely. The key benefits are: 
d. Reduced energy costs:No city can simply switch off its lights at night, so other measures are called for. Not every street and road requires full illumination all the time. Therefore, depending on the site and situation, a frequently feasible option is to dim lights, thereby striking a balance between economical goals and citizens' safety needs. Dimming lights by up to 50 percent is generally imperceptible to the human eye and can show a 40 percent reduction in power use. Typically, lights would be dimmed during non-peak activity times between $11 \mathrm{pm}$ and $5 \mathrm{am}[18]$

e. Reduced greenhouse gas emissions: With the energy savings comes a corresponding reduction in our community's $\mathrm{CO}_{2}$ footprint. Each saving of $1500 \mathrm{kWh}$ reduces $\mathrm{CO}_{2}$ emissions by approximately 1 ton for mixed power generation [7].

f. Reduced maintenance costs: By automatically monitoring the mortality curve of each lamp fixture in a streetlight network, you can accurately predict lamp failures before they occur. This enables us to develop more efficient and cost-effective maintenance scheduling. Also, by intelligent control of the lamp, we can optimize the life-span.

g. Higher community satisfaction: With an intelligent streetlight system in place, you will be able to significantly improve the performance, efficiency and reliability of the street lighting in your community. No longer do you need to rely on public complaints and visual inspections after sunset to monitor streetlight function and safety. Through its energy and maintenance reduction capabilities, you will also be able to free up a large allocation of public funds that could then contribute towards other community programs [18].

h. Fast payback: Intelligent streetlight systems are very cost-effective, with a typical payback period within five years. By first replacing the oldest lamps that have the most inefficient technology, this period can be shortened still further.

i. Information: Information is an increasingly valuable asset. If you can capture data on ambient temperature, moisture, visibility, light intensity, rain and traffic density, you can further lower energy costs and roll out new services for your customers. These innovative applications can add further value to your intelligent lighting system.

\subsection{Mature Technologies Have Now Converged}

Until relatively recently, intelligent lighting networks have been small-scale systems utilizing expensive technologies and having a poor Return On Investment (ROI). This has made them unsuitable for more general municipal lighting control. Many key technologies have now matured to bring low-cost sustainable intelligent lighting.

Lamp technology has been improving in efficiency and performance for the past 30 years. Lamp control has become more efficient with the move from mechanical ballasts to electronic ballasts, and the lamp technology has evolved from High Intensity Discharge (HID) Mercury vapor to Sodium and metal halide. The recent developments in LED technology have resulted in a further leap in efficiency [6].

LED street lighting technology has finally arrived, meeting standard regulations for environmental challenges, as well as improving streetlight quality through features like reduced glare and better color rendering. Current LED solutions have a low power consumption of 67W (Phillips Luxeon Rebel) and offer energy savings of as much as 52 percent over Mercury Vapor HID and 26 percent over a sodium HID fixture (90W). LEDs have a much higher initial cost, but the longer lifetime of 60000 hours translates into a 10- to 15year lifetime, which is at least triple, that of HID lamps. This reduces maintenance costs and, combined with the energy savings, means that municipalities can recoup the costs of a basic non-networked LED-based street lighting installation in four to six years. LEDs also facilitate low-cost dimming control when compared to the expense of adding dimmable electronic ballasts to HID lamps [18].

\subsection{Jennic's Technology For Intelligent Lighting}

Jennic manufacture wireless microcontrollers, and have developed the JenNet networking software which handles all the network traffic and manages network faults with a self-healing mechanism. This software is now field-proven in very large networks. Some of the key benefits of Jennic solution are Lowest cost of ownership ,no hidden engineering costs, no license costs, ease of installation, secure communications, Scalability, Global deployment, future proof architecture, value added features, Increased energy savings etc.

\section{How it works}

a. The short range of wireless communication is overcome in a network by hopping messages up and down the network. In this way, ranges of many tens of $\mathrm{km}$ can be achieved using low-cost radio technology.

b. Streetlights are ideal for wireless communication because they have the height, which enables wireless service coverage of $350 \mathrm{~m}$ or more, and the spacing of streetlights means that many lights are in range of each other. Hence, if a node were to fail, an alternative route could be found. The streetlights must be powered, so this energy is also available for the wireless streetlight controller. 


\section{Conclusion}

The purpose of this research is to obtain optimal design for high mast poles through material selection and design criteria of high mast poles, environmental conditions for placement, economy and commissioning. The material opted in this paper is mild steel due to its ductility, strength and other advantages. The design optimal is observed by considering sections of pole like solid circular, hollow circular, rectangular, I-section and tapered circular hollow section. Among them tapered circular hollow section is preferred as it yields optimal solutions. By this, the procedure is determined to obtain diameter of high mast pole and foundation bolts of a pole. This is done through analysis in solid works by fixing the base section and applying compressive loads on the top section of the pole. The maximum stress is found to be $18277.3 \mathrm{~N} / \mathrm{mm}^{2}$ and deformation is 0.00140177 $\mathrm{mm}$ which is utmost safe under the factor of safety as 1 . Hence, a procedure is also introduced to optimize and commission high mast lighting poles by Jennics Technology of intelligent lighting system which explains JenNet networking software which handles all the network traffic and manages network faults with a selfhealing mechanism.

\section{Future Scope}

The Research could be further extended through the installation of photo voltaic solar panels on High Mast Poles, so that it will help in the reduction of energy usage and $\mathrm{CO}_{2}$ emissions. This could be achieved by installing the panels as a separate section on the top of the high mast poles or installing them on the hexagonal sides of the pole so that it could absorb the light throughout the day in any direction.

\section{References}

[1] O.Rabaza, A.Pena-Garcia, F.Perez-Ocon, D.Gomez-Lorenete, ASimple Method for designing efficient public lighting, based on new parameter relationship, Expert Systems with Applications, 40(18), 2013, 7305-7315

[2] G.Das, S.Chakrabarty, A.K. Dutta, S.K. Das, K.K. Gupta, R.N. Ghosh, Failure analysis of a high mast lamp post, Engineering Failure Analysis, 13(17), 2006, 1153-1158.

[3] A Louise, Alexander, J. Wood, A study of the low-cycle fatigue failure of galvanized steel lighting column, Engineering Failure Analysis, 16(7), 2009, 2153-2162.

[4] Amir Fam, Je-Kuk Son, Finite element modeling of hollow and concrete-filled fiber composite tubes in flexure: Optimization of partial filling and a design method for poles, Engineering Structures, 30(10), 2008, 2667-2676.

[5] MiomirKostic, LidijaDjokic, DejanPojatar, NatasaStrbac-Hadzibegovic, Technical and economic analysis of road lighting solutions based on mesopic vision, Building and Environment, 44(1), 66-75.

[6] Min-Wook Kang, Manoj K. Jha, Paul Schonfeld, Applicability of Highway alignment optimization models, Transportation Research Part C: Emerging Technologies, 21(1), 2012, 257-286.

[7] Jeremy Lagorse, Damien Paire, AbdellatifMiraoui, Sizing Optimization Of a Stand-alone street Linghting System powered by hybrid system using fuel cell, pv and battery, Renewable Energy, 34(3), 2009, 683-691.

[8] MiomirKostic, LidijaDjokic, Recommendations for energy efficient and visually acceptable street lighting, Energy, 34(10), 2009, $1565-1572$

[9] Y.F. Al-Obaid, The automated analysis of prestressed concrete poles for street lighting, Engineering Fracture Mechanics, 34(5), 1989, 1031-1040.

[10] L. Carlsson, B. Knave, R. Wibom, Exposure to and effects of glare from high mast lighting on workers at a timber terminal, Applied Ergonomics, 14(4), 1983, 271-278.

[11] R.O. Ritchie, J.F. Knott, J.R. Rice, On the relationship between critical tensile stress and fracture toughness in mild steel, Journal of the Machanics and physics of Solids, 21(6), 1973, 395-410.

[12] P.Kannaiah, N.Sidheswar, V.V.S.Sastry, Machine drawing (Tata McGraw-Hill, 2009)

[13] R.S Khurmi, J.K Gupta, Machine design (Eurasia Publishing House, 2005)

[14] P.Kannaiah, Design Of Machine Elements (Scitech Publications Pvt Ltd, 2006)

[15] D. Wilken, European Road Lighting Technologies (DIANE Publishing, 2001)

[16] American Association of State highway and transportation officials, Roadway Lighting Design Guide (AASHTON, 2005)

[17] R.J. Connor, National Research Council (U.S), Transportation Research Board, Fatigue Loading and Design Methadology for High-Mast Lighting Tower (Transportation Research Board, 2012)

[18] C.A. Edwards, The Structure and properties of Mild Steel (J.G.Miller, 2006) 